\title{
Outcome of Treatment of Tuberculosis in HIV Infected Persons in the Era of Highly Active Antiretroviral Therapy (HAART) as Seen in the Second City Tuberculosis Hospital in Saint Petersburg, Russia
} Auwal Yola*, Alexandr Panteleev and Tamara Sologub

Address: Department of Infectious diseases and Tropical Medicine, Medical Academy, Saint Petersburg 191144, Russia

Email: Auwal Yola* - auwalyola@yahoo.com

* Corresponding author

from 2005 International Meeting of The Institute of Human Virology Baltimore, USA, 29 August - 2 September 2005

Published: 8 December 2005

Retrovirology 2005, 2(SuppI I):SI35 doi:I0.I I86/I742-4690-2-SI-SI35

\section{Background}

Tuberculosis (TB) is the leading cause of morbidity and mortality among persons with HIV/AIDS in highly affected regions including Russia. Despite the fact that Russia has the infrastructure for the treatment of TB unlike developing countries, authorities are not yet paying attention to provide antiretroviral treatment for these category of people who are mostly IDU users, former prisoners and jobless. As such the benefit of highly active antiretroviral therapy (HAART) in the treatment of patients co-infected with tuberculosis (TB) and human immunodeficiency virus (HIV) has never been explored in this country.

\section{Objective}

To assess the risks and benefits of administering highly active antiretroviral therapy (HAART) during the treatment of tuberculosis (TB) in HIV-infected patients.

\section{Materials and methods}

53 HIV-infected persons diagnosed with active TB were recruited in the special HIV and TB unit of the second city tuberculosis hospital in Saint- Petersburg, Russia into an observational, prospective study aimed to evaluate tuberculosis treatment outcomes between Dec.2003 and March 2005. Only 15 patients (28.3\%) with a median CD4 cell count of 235 cells $/ \mathrm{mm}^{3}$ were on ART (AZT+3TC+EFV), while the rest $38(71.7 \%)$ with a median $\mathrm{CD} 4$ cell count of 267 cells $/ \mathrm{mm}^{3}$ received antituberculosis medications only. Clinical and immunologic responses were assessed within the two groups by comparing incidence of new AIDS-associated opportunistic illnesses (OIs), adverse events and CD4 cells dynamics.

\section{Results}

Among antiretroviral patients, CD4 cell count increased to 297 cells $/ \mathrm{mm}^{3}$ versus a decrease to $212 \mathrm{cell} / \mathrm{mm}^{3}$ in patients on anti-tuberculosis treatment alone $(\mathrm{p}=0.10)$. The risk for HIV progression to new OIs was lower among antiretroviral group ( 3.5 versus $24.5 \%$; relative risk $(\mathrm{RR})=$ 0.14 . Adverse events (AE) occurred in $3(20 \%)$ of the 15 patients on antiretroviral, all with a CD4 cell count of $<$ 100 cells $/ \mathrm{mm}^{3}$ and one patient interrupted HIV medication. The majority of $\mathrm{AE}$ occurred within the first 2 months, with anemia, increased cough, rash and gastrointestinal upset occurring most commonly.

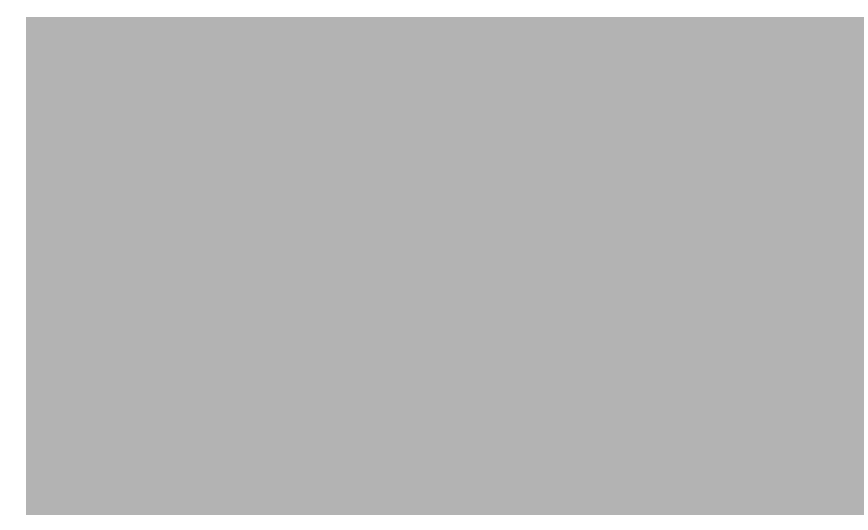

Figure I

CD4 cell dynamics in HAARTAnti -TB and Anti -TB only patients. 


\section{Conclusion}

HAART substantially reduced new AIDS events and improved CD4 cells count in HIV-TB co-infected patients. Those with a CD 4 cell count $<100$ cells $/ \mathrm{mm}^{3}$ have a high event risk during the intensive phase of anti-TB treatment. These pilot data should be taken into account when deciding to initiate HAART in co-infected patients with CD4 cell counts $<100$ cells $/ \mathrm{mm}^{3}$. 